\title{
Enhancement of mammary tumour growth by IGFBP-3 involves impaired $T$ cell accumulation
}

\author{
Tiffany Scully1,*, Carolyn D Scott', Sue M Firth', Lisa M Sedger ${ }^{2}$, John E Pintar ${ }^{3}$, Stephen M Twigg ${ }^{4}$ and \\ Robert C Baxter ${ }^{1}$
}

${ }^{1}$ Hormones and Cancer Laboratories, Kolling Institute, University of Sydney, Royal North Shore Hospital, St Leonards, New South Wales, Australia 25 chool of Life Sciences, Faculty of Science, University of Technology Sydney, Ultimo, New South Wales, Australia ${ }^{3}$ Department of Neuroscience and Cell Biology, Rutgers Robert Wood Johnson Medical School, New Jersey, USA ${ }^{4}$ Charles Perkins Centre, Sydney Medical School, University of Sydney, New South Wales, Australia

Correspondence should be addressed to R C Baxter: robert.baxter@sydney.edu.au

*(T Scully is now at Division of Endocrinology, Diabetes and Bone Diseases, Icahn School of Medicine at Mount Sinai, New York, New York, USA)

\begin{abstract}
Epidemiological studies show an association between obesity and poor breast cancer prognosis. We previously demonstrated that global IGFBP-3 deficiency, in IGFBP-3-null mice, resulted in a $50 \%$ reduction in mammary tumour growth over 3 weeks relative to tumours in wild-type (WT) C57BL/6 mice. This growth reduction was ameliorated by high fat feeding-induced obesity. This study aimed to examine how IGFBP-3 promotes tumour growth by influencing the immune tumour microenvironment in healthy and obese mice. Syngeneic EO771 cells, which lack detectable IGFBP-3 expression, were grown as orthotopic tumours in WT and IGFBP-3-null C57BL/6 mice placed on either a control chow or a high-fat diet (HFD), and examined by quantitative PCR and immunohistochemistry. In WT mice, increased stromal expression of IGFBP-3 was positively associated with tumour growth, supporting the hypothesis that IGFBP-3 in the microenvironment promotes tumour progression. Examining markers of immune cell subsets, gene expression of Ifng, Cd8a, Cd8b1 and Tnf and CD8 measured by immunohistochemistry were elevated in tumours of IGFBP-3-null mice compared to WT, indicating an accumulation of CD8+ T cells, but this increase was absent if the IGFBP-3-null mice had been exposed to HFD. Expression of these genes was negatively associated with tumour growth. Although similar among groups overall, $\mathrm{Nkg} 2 \mathrm{~d}$ and $\mathrm{Tnfsf10}$ tumoural expression was associated with decreased tumour growth. Overall, the results of this study provide an immunebased mechanism by which host IGFBP-3 may promote breast tumour growth in the EO771 murine breast cancer model, and suggest that targeting IGFBP-3 might make a novel contribution to immune therapy for breast cancer.
\end{abstract}

\section{Introduction}

Epidemiological studies have shown an association between obesity and poor breast cancer prognosis (Protani et al. 2010, Chan et al. 2014, Renehan et al. 2015). While various mechanisms have been proposed to explain the link between obesity and worsened breast cancer progression, much remains to be understood. The mechanisms proposed include obesity-related changes in the adipose tissue surrounding the mammary gland, 
changes in the profile of adipokines secreted, an increase in insulin-IGF-1 signalling and sex hormone regulation (Park et al. 2014, Iyengar et al. 2015, Renehan et al. 2015).

Insulin-like growth factor-binding protein-3 (IGFBP-3) is one of the six circulating carrier proteins for peptides of the IGF family, which are ligands for the oncogenic receptor tyrosine kinase, the type 1 IGF receptor. Complementing their role in IGF transport, IGFBPs have multiple cellular actions, some of them independent of IGF binding, and may be either stimulatory or inhibitory to oncogenic processes in different tissues and cancer types (Baxter 2014). Of the six IGF binding proteins, IGFBP-3 is the predominant IGF transporter, accounting for at least $75 \%$ of the IGFs in circulation (Firth \& Baxter 2002). Increased levels of circulating IGFBP-3 have been associated with both increased body mass index (Rowlands et al. 2010) and an increased risk of premenopausal breast cancer (Renehan et al. 2004) as well as recurrence of disease in postmenopausal women (Goodwin et al. 2002), suggesting a possible role for IGFBP-3 in the progression of breast cancer. High tumoural expression of IGFBP-3 has also been associated with poorer prognosis (Yu et al. 1996, Rocha et al. 1997, Sheen-Chen et al. 2009), which may in part be driven by oncogenic pathways activated by IGFBP-3 (Baxter 2014, Martin et al. 2014). In a previous study utilising IGFBP-3 global knock-out (BP3KO) mice in conjunction with high fat feeding, we demonstrated that IGFBP-3 deficiency resulted in reduced mammary tumour growth, and this effect was ameliorated by high fat feeding (Scully et al. 2016). As part of investigating how tumour growth is reduced in the absence of host IGFBP-3, tumours grown in $\mathrm{BP} 3 \mathrm{KO}$ mice were observed to contain increased numbers of CD3+ $\mathrm{T}$ cells (Scully et al. 2016). This observation suggested that IGFBP-3 influences tumoural $\mathrm{T}$ cell infiltration, a previously unknown property that might further implicate IGFBP-3 in the regulation of tumour progression.

In women with breast cancer, a high percentage of tumour-infiltrating lymphocytes in the tumour stroma has been positively associated with increased survival (Mahmoud et al. 2011) with the association applying across various breast cancer subtypes (Ali et al. 2014, Ibrahim et al. 2014). In particular, the presence of lymphocytes within breast tumours has been shown to be an independent predictor of pathological complete response to chemotherapy (Denkert et al. 2010). There is, therefore, a high level of interest in the development and potentiation of an anti-tumour immune response as a therapeutic approach for breast cancer (Kroemer et al. 2015, Savas et al. 2016).
To further develop our understanding regarding the influence of IGFBP-3 on immune cell behaviour during tumour growth, the experiments detailed in this study aimed to investigate how IGFBP-3 might influence the immune component of the tumour microenvironment.

\section{Materials and methods}

\section{Mice and tumour cells}

Animal studies were approved by the Northern Sydney Local Health District Animal Care and Ethics Committee (Protocol 1305-003A) and were conducted as previously described (Scully et al. 2016). Briefly, a colony of IGFBP-3 global knock-out (BP3KO) mice bred onto a C57BL/6 background (Ning et al. 2006) was established at the Kolling Institute. Six-week-old female BP3KO and wildtype (WT) C57BL/6 mice were placed on either a control chow diet (6\% fat, 23\% protein; Gordon's Specialty Feeds, Yanderra, NSW, Australia) or a HFD (47.7\% fat, $19.5 \%$ protein; prepared in-house), for 15 weeks. After a 15-week feeding period, mice were injected with the mouse mammary tumour cell line, EO771 (syngeneic with C57BL/6 mice), provided by Prof. Robin Anderson, Peter MacCallum Cancer Centre, Melbourne, Australia. Cells $\left(5 \times 10^{5}\right)$ were injected into the fourth left mammary gland. Mice were killed when the largest tumour reached $1000 \mathrm{~mm}^{3}$. Tumours were excised and either snap-frozen in liquid nitrogen or placed into 10\% neutral buffered formalin (POCD Scientific, Artarmon, NSW, Australia) for further analysis.

\section{Gene expression analysis}

Total RNA from tumours was extracted with TRIzol reagent (Thermo Fisher, Scoresby, VIC, Australia) and purified with Direct-zol RNA MiniPrep (Zymo Research, Irvine, CA, USA). RNA was quantitated using Nanodrop ND-1000 Spectrophotometer (NanoDrop Technologies, Wilmington, DE, USA) and reverse-transcribed with Maxima H Minus Reverse Transcriptase (Thermo Fisher) according to the manufacturer's instructions. Quantitative real-time PCR was performed in an ABI 7900HT (Applied Biosystems) using Taqman probes (Applied Biosystems) for murine CD8 $\alpha$ (Cd8a; Mm01182108_m1), CD8 $\beta 1$ (Cd8b1; Mn00438116_m1), CD4 (Cd4; Mm00442754_ $\mathrm{m} 1)$, Interferon- $\gamma \quad$ (Ifng; Mm01168134_m1), TNF (Tnf; Mm00443258_m1), FOXP3 (Foxp3; Mm00475162_ m1), NKG2D (Klrk1; Mm00473603_m1) and TRAIL (Tnfsf10; Mm01283606_m1). Transcripts for each sample 
were assayed in triplicate and quantitated relative to hydroxymethylbilane synthase (Hmbs; Mm01143545) for tumour samples.

\section{Immunohistochemical (IHC) analysis}

Tissues were fixed in formalin for $24 \mathrm{~h}$ and paraffinembedded. Four-micrometre sections were deparaffinised and antigen retrieval was performed using a water bath with either citrate buffer, $\mathrm{pH} 6$ (for granzyme B) or TrisEDTA buffer, pH 9 (CD8a). Sections were boiled in retrieval buffer for $20 \mathrm{~min}$, and then cooled for $20 \mathrm{~min}$. Using an automated slide stainer (Dako Australia), sections were quenched with hydrogen peroxide, incubated with primary antibody and then secondary antibody (K4003, Dako) and revealed with ImmPact NovaRed Peroxidase Substrate (Vector Laboratories, Burlingame, CA, USA). Sections were counterstained in Mayer's haematoxylin. Primary antibodies used were anti-CD8 $\alpha$ (\#14-0808, Affymetrix eBioscience, $1 \mu \mathrm{g} / \mathrm{mL}$ ) and anti-Granzyme B (\#ab4059, Abcam, $1.8 \mu \mathrm{g} / \mathrm{mL}$ ). Images were analysed using CellProfiler software (Broad Institute, MA, USA) as previously described (Scully et al. 2016). The data are presented as the number of positively stained cells as a proportion of the total number of cells present in the fields of view examined.

\section{Statistical analysis}

ANOVA was performed using GraphPadPrism v.6.00 for Windows (GraphPad Software). Statistical significance was determined by 2-way ANOVA followed by post hoc Tukey's test, Kruskal-Wallis test, $t$-test or by Spearman's correlation test, as indicated.

\section{Results}

We have previously reported (Scully et al. 2016) that the growth of EO771 murine mammary tumour cells implanted orthotopically in IGFBP-3-deficient mice (BP3KO) mice fed a control chow diet was inhibited relative to tumours grown in WT mice fed either a control diet or 15 weeks of HFD (Scully et al. 2016) (Table 1). Tumours from chow-fed BP3KO mice were 50\% smaller in both weight and volume compared to tumours from chow-fed WT mice (chow-fed WT vs BP3KO: $P<0.05$, post hoc Tukey's test). This tumour growth-inhibitory effect of circulating and/or stromal IGFBP-3 deficiency was reversed with high fat feeding, as high fat-fed BP3KO mice showed tumour growth similar to WT mice (Table 1) (Scully et al. 2016). The tumours grown in the BP3KO mice were observed to show an increased presence of $\mathrm{T}$ cells based on the expression of CD3, a pan T cell marker. To extend these findings, representative tumours from 15 to 16 mice per group were examined for protein and gene expression analysis of various markers including those associated with specific subsets of T cells.

EO771 cell tumours are ideal for demonstrating effects of host-derived (circulating or stromal) IGFBP-3, as they lack detectable endogenous IGFBP-3 expression. Figure 1A and $\mathrm{B}$ illustrates the absence of IGFBP-3 mRNA and protein in E0771 cells in vitro. Despite the lack of $I g f b p 3$ mRNA in the implanted tumour cells, Igfbp3 mRNA was detectable in tumours growing in WT mice, indicating that it originated from host cells within the tumour microenvironment. An increased expression of $I g f b p 3$ was associated with increased tumour weight (Fig. 1C) consistent with $I g f b p 3$ within the tumour microenvironment promoting tumour growth. In contrast to the positive relationship between stromal IGFBP-3 expression and tumour weight, there was no correlation between circulating IGFBP-3 and either tumour weight or stromal mRNA levels of IGFBP-3 in the WT mice (data not shown).

Gene expression of the $\mathrm{T}$ cell markers, $\mathrm{Cd} 8 \mathrm{a}$ and $C d 8 b 1$, was elevated in tumours from $\mathrm{BP} 3 \mathrm{KO}$ mice (Fig. 2A) (Cd8a: $P<0.0001$ for genotype) in both chowfed (WT: $1.00 \pm 0.19$ vs BP3KO: $2.20 \pm 0.28$ ) and HFD mice (WT: $0.73 \pm 0.11$ vs BP3KO: $1.48 \pm 0.24$ ). The exposure to HFD resulted in decreased expression of $C d 8 a$ in tumours from both genotypes ( $P=0.023$ for diet, 2-way ANOVA). Similar to the results obtained with $C d 8 a$, tumours from chow-fed BP3KO mice showed increased mRNA levels of

Table 1 EO771 mammary tumour growth in wild-type and BP3KO mice fed a normal or high-fat diet.

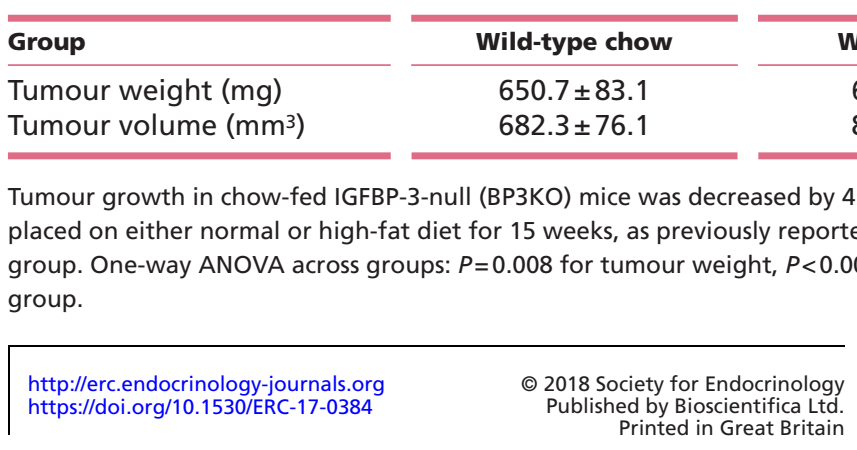

\begin{tabular}{ccc}
\hline BP3KO chow & & BP3KO HFD \\
\hline $320.3 \pm 59.6 *$ & & $582.5 \pm 74.7$ \\
$338.8 \pm 55.6 *$ & & $540.6 \pm 59.4$
\end{tabular}
Wild-type

$688.3 \pm 67.1$

$875.9 \pm 81.2$

th high-fat (HFD) fed BP3KO mice, and wild-type mice placed on either normal or high-fat diet for 15 weeks, as previously reported (Scully et al. 2016). Data are presented as mean values \pm s.E.M., $n=22-35$ per group. One-way ANOVA across groups: $P=0.008$ for tumour weight, $P<0.0001$ for tumour volume. $P$ ost hoc Tukey's test: ${ }^{\star} P<0.05$ vs wild-type chow 
A

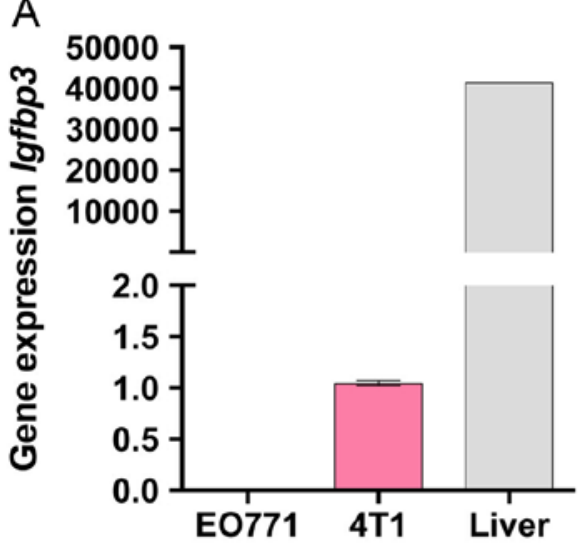

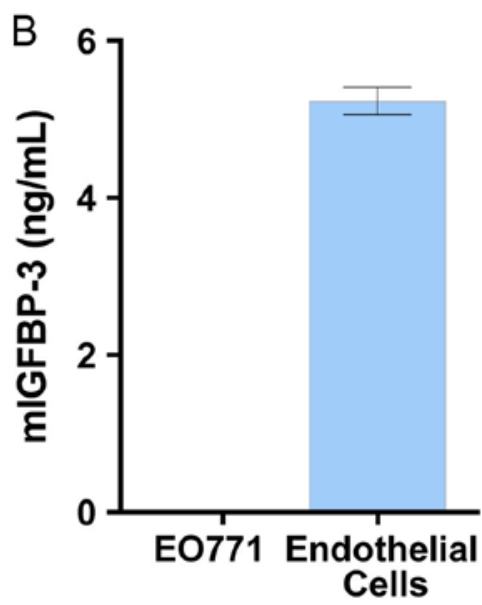

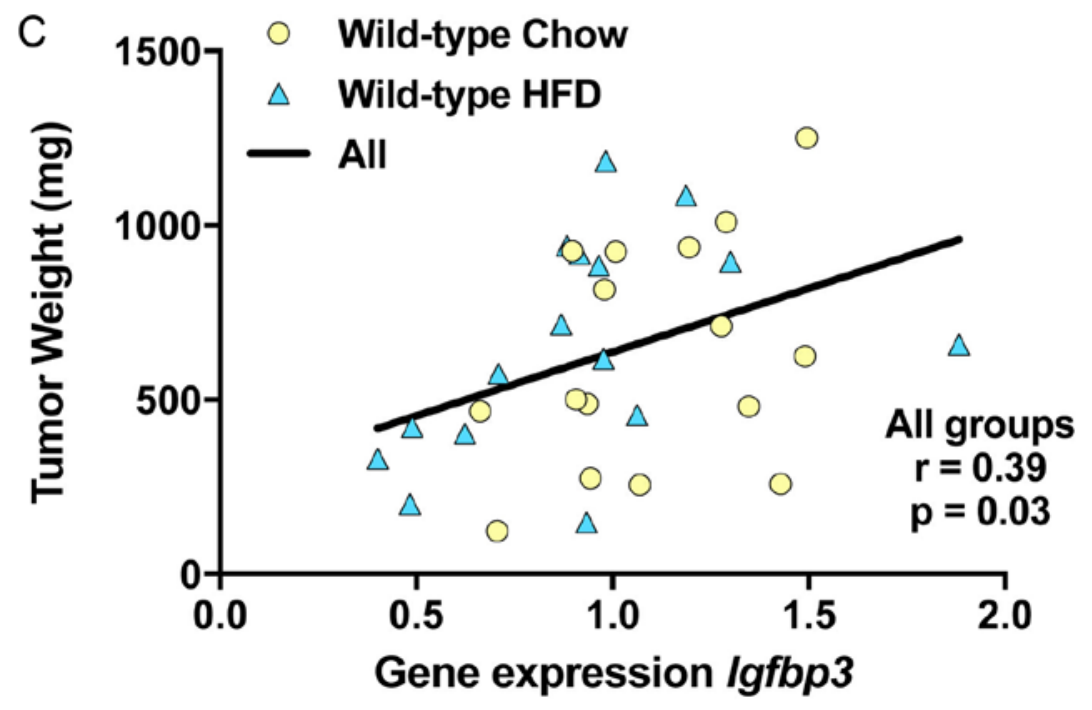

Figure 1

EO771 cells do not express detectable IGFBP-3 as determined by (A) mRNA expression compared to murine 4T1 breast cancer cells (normalised to 1.0) and mouse liver and (B) secreted IGFBP-3 in culture medium, measured by ELISA in comparison to mouse cardiac endothelial cells. Comparisons made against 4T1 and endothelial cells were conducted in triplicate. Data are presented as means \pm S.E.M. (C) Increased intratumoural mRNA expression of Igfbp 3 relative to $\mathrm{Hmbs}$ associated with increased tumour weight ( $n=16$ per group). Data were analysed by Spearman's correlation test.
$C d 8 b 1$ which was reduced with exposure to HFD (Fig. 2A) (Cd8b1: $P<0.0002$ for genotype and $P=0.008$ for diet, 2 -way ANOVA). These findings indicate that the absence of IGFBP-3 increases and exposure to HFD decreases CD8 $\mathrm{T}$ cell infiltration into tumours. In accordance with the clinical literature showing that increased $\mathrm{T}$ cell infiltration is associated with improved patient outcome (Mahmoud et al. 2011, Ali et al. 2014), gene expression of both Cd8a (Fig. 2B) and Cd8b1 (Fig. 2C) was associated with decreased tumour weight. The mRNA expression of the $\mathrm{T}$ cell marker $C d 4$ was increased in tumours grown in BP3KO mice as well as mice that were high fat-fed ( $P=0.035$ for genotype and $P=0.020$ for diet, 2-way ANOVA). The increased levels of $\mathrm{CD}^{+} \mathrm{T}$ cells previously observed in the tumours grown in chow-fed BP3KO mice (Scully et al. 2016) are likely due to greater levels of CD8expressing $\mathrm{T}$ cells as opposed to CD4-expressing $\mathrm{T}$ cells, as suggested by an increased intratumoural Cd8b1:Cd4 ratio compared to WT mice on both diets and high fat-fed BP3KO mice (Fig. 2D) ( $P=0.028$ for genotype and $P<0.001$ for diet, 2-way ANOVA). Similar results were obtained with $C d 8 a: C d 4$ ratio. The distribution of $C d 8 b 1$ and Cd4 mRNA expression under different experimental conditions is illustrated as the sum of CD4 and CD8 expressions in Fig. 2E.

The increased gene expression of $C d 8 a$ in tumours grown in the absence of IGFBP-3, with partial reversal in high fat-fed mice, was confirmed by immunohistochemistry using an antibody directed to the CD8 $\alpha$ antigen. The presence of CD $8 \alpha^{+}$cells by IHC was found to be similarly elevated in the absence of IGFBP-3 $(P=0.008$ for genotype, 2-way ANOVA) and decreased by HFD feeding ( $P=0.032$ for diet, 2-way ANOVA) (Fig. 3A). The gene expression of $C d 8 a$ was highly correlated with the percentage of CD8 $\alpha^{+}$cells in tumour sections (Fig. 3B). Representative images of stained sections show that the abundance of CD8 $\alpha^{+}$cells is increased in the tumours of chow-fed BP3KO mice compared to high fat-fed BP3KO 
B

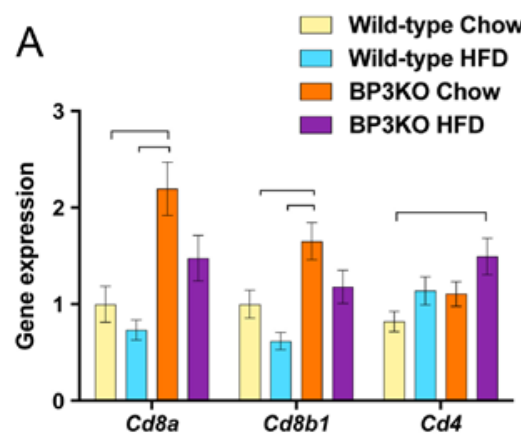

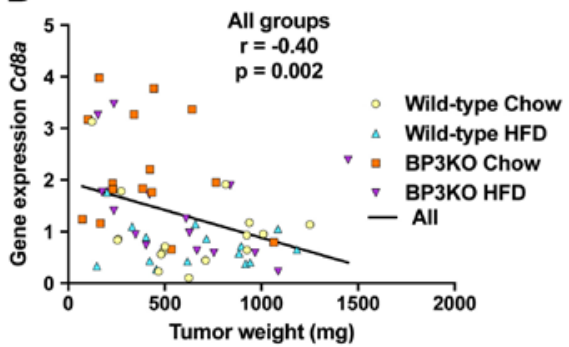

D

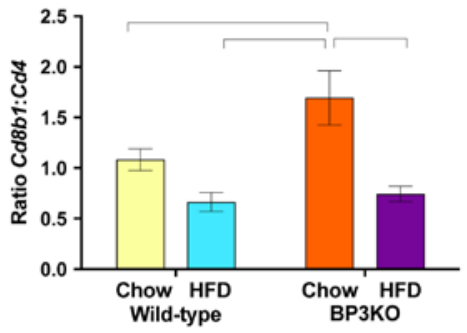

C

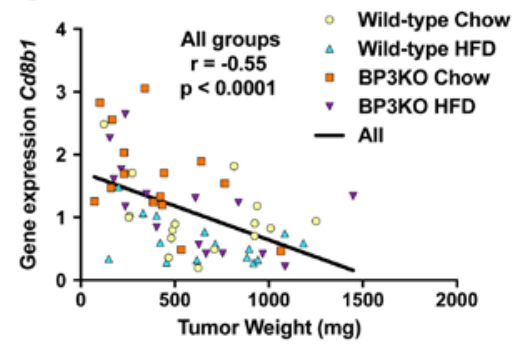

E

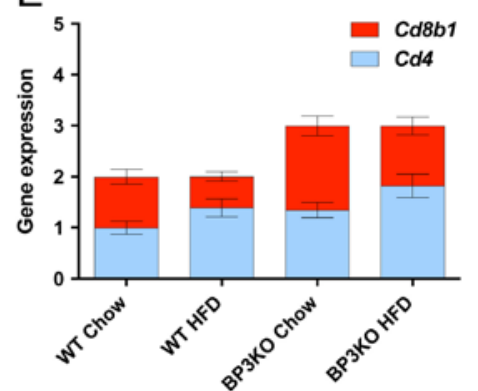

Figure 2

Intratumoural T cell abundance is increased in the absence of IGFBP-3. (A) Gene expression of the T cell markers, Cd8a and Cd8b1, is increased in tumours from BP3KO mice but reduced by HFD (Cd8a: $P<0.0001$ for genotype and $P=0.023$ for diet, $C d 8 b 1: P<0.0002$ for genotype and $P=0.008$ for diet, $n=15-16$ per group). Gene expression of the T cell marker, $C d 4$, is increased in tumours from high fat-fed as well as BP3KO mice ( $P=0.035$ for genotype and $P=0.02$ for diet, $n=14-16$ per group). (B and C) Cd8a and Cd8b1 gene expressions in the tumour are negatively associated with tumour weight across all groups. (D) The ratio of cells expressing Cd8b1:Cd4 mRNA is increased in chow-fed BP3KO mice $(P=0.028$ for genotype and $P<0.001$ for diet). (E) Combined gene expression of $C d 8 b 1$ and $C d 4$ in tumours from wild-type and BP3KO mice. Data were analysed by 2 -way ANOVA or by Spearman's correlation test and are shown as means \pm S.E.M. Brackets indicate groups that are significantly different by post hoc Tukey's test.

mice and WT mice on either diet (Fig. 3C, D, E and F). Overall, these findings are consistent with the hypothesis that the reduced tumour growth observed in the $\mathrm{BP} 3 \mathrm{KO}$ mice is related to an increase in T cell infiltration. Thus, IGFBP-3 may have a previously unrecognised role in suppressing tumour $\mathrm{T}$ cell abundance in vivo.

To determine if the increased presence of CD8+ $\mathrm{T}$ cells in the tumours of BP3KO mice is associated with an increase in cytotoxic activity, mRNA levels of the serine protease granzyme B, Gzmb, were measured. Gzmb gene expression was found to be similar overall between WT and BP3КO mice but diet appeared to have an effect on Gzmb expression in the BP3KO mice $(P=0.024$ for interaction) (Fig. 4A). In mice fed HFD, the expression of $G z m b$ was reduced by $25 \%$ in the tumours of BP3KO mice (Fig. 4A) (chow-fed vs HFD: $1.30 \pm 0.09$ vs $0.98 \pm 0.07$, $P=0.009$, $t$-test). The number of granzyme $\mathrm{B}^{+}$cells as a proportion of the total number of cells present in the tumour sections from WT and BP3KO on either diet was observed to be similar overall by immunohistochemistry (Fig. 4B). Representative images of a positively stained tumour section from a high fat-fed WT mouse with its stained negative isotype control are shown (Fig. 4C).
Gzmb mRNA expression was associated positively with Cd8b1 expression (Fig. 4D) and negatively with tumour weight (Fig. 4E).

Using forkhead box P3 (FOXP3) as a marker of T-regulatory cells (Shevach 2009), Foxp3 gene expression was found to be similar across groups (Fig. 4A). Natural killer (NK) cells have been shown to be involved in the immune response to breast cancer where breast cancer progression is associated with a decrease in NK cellmediated cytotoxic activity (Mamessier et al. 2011). NKG2D, also known as killer cell lectin-like receptor $\mathrm{K} 1$, is a trans-membrane protein that is a marker of activated NK cells and NK T cells. Intratumoural expression of $\mathrm{Nkg} 2 \mathrm{~d}$ mRNA was not different among the treatment groups (Fig. 4A) (WT Chow: $0.83 \pm 0.09$ vs WT HFD: $0.84 \pm 0.13$ vs BP3KO Chow: $1.00 \pm 0.08$ vs BP3KO HFD: $0.95 \pm 0.10$ ) but was associated with decreased tumour weight (Fig. 4F).

The cytokines, interferon gamma (IFN $\gamma$ ) and tumour necrosis factor (TNF; TNFSF2) have been reported either individually or in tandem (Braumuller et al. 2013, Matsushita et al. 2015) to exert anti-tumour effects which include the induction of tumour cell apoptosis and cell cycle arrest. Therefore, as part of investigating how the 

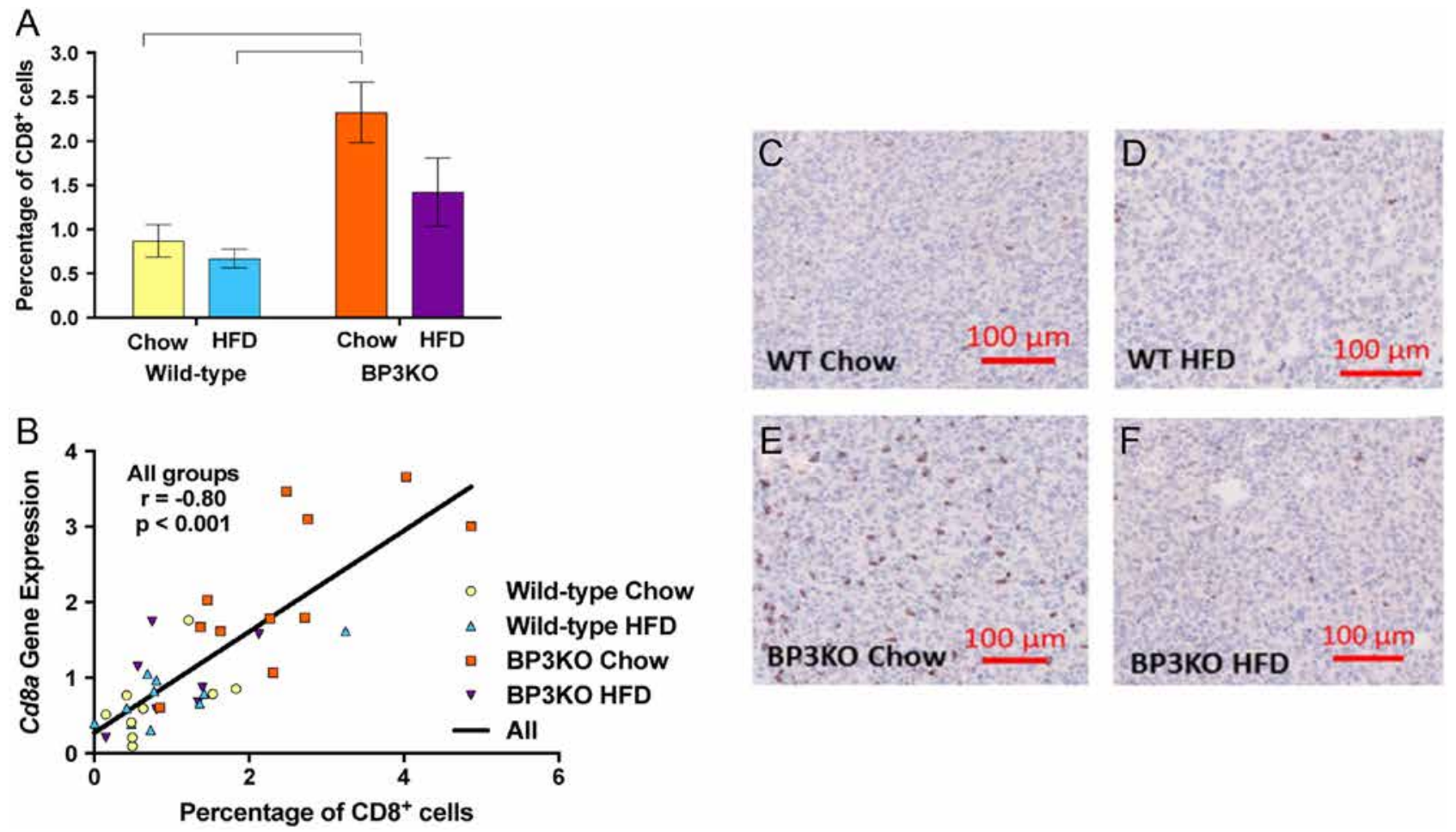

Figure 3

(A) The proportion of CD8 ${ }^{+} \mathrm{T}$ cells, identified by immunohistochemistry, is increased in tumours from BP3KO mice and reduced by HFD ( $P=0.008$ for genotype and $P=0.032$ for diet, $n=11-15$ per group). (B) Cd8a gene expression is strongly associated with CD8 staining by IHC. (C, D, E and F) Representative images of tumour sections stained for CD8. Data were analysed by 2-way ANOVA or by Spearman's correlation test and are shown as means \pm S.E.M. Brackets indicate groups that are significantly different by post hoc Tukey's test.

increased intratumoural $\mathrm{T}$ cell infiltration observed in the absence of IGFBP-3 might be associated with the decrease in tumour growth, the mRNA levels of the cytokines, IFN $\gamma$ and TNF were examined. As shown in Fig. 5A, the expression of Ifng was increased in tumours grown in BP3KO mice independent of diet (chow: $1.00 \pm 0.16$ vs $1.87 \pm 0.27$ and HFD: $1.06 \pm 0.14$ vs $1.33 \pm 0.23 ; P=0.008$ for genotype, 2-way ANOVA), and the significant increase in tumour Ifng mRNA seen in BP3KO mice fed a chow diet was absent on HFD feeding. Similar to Ifng, but less pronounced, intratumoural gene expression of Tnf was increased in the absence of IGFBP-3 (Fig. 5A) $(P=0.049$ for genotype). This increase was more obvious (although not significant by post hoc testing) in chow-fed mice (WT vs BP3KO: $0.85 \pm 0.08$ vs $1.2 \pm 0.15$ ) with similar gene expression in high fat-fed mice $(0.84 \pm 0.10$ vs $0.93 \pm 0.08)$. The increased expression of Ifng was associated with decreased tumour weight in BP3KO, but not WT, mice (Fig. 5B), suggesting that IFN $\gamma$ may be involved in the decreased tumour growth observed in the BP3KO mice. The increased intratumoural mRNA levels of Tnf were associated with decreased tumour weight (Fig. 5C). TNFrelated apoptosis-inducing ligand (TRAIL), encoded by Tnfsf10, is a cytokine belonging to the TNF superfamily. TRAIL, which is IFN-inducible (Sedger et al. 1999) and directly tumouricidal (Sedger et al. 2002) with the ability to control tumour growth and metastasis in vivo (Smyth et al. 2001), was also examined. Gene expression of TRAIL was overall similar in tumours from both WT and BP3KO mice, independent of diet (Fig. 5A). Consistent with its association with NK cells (Smyth et al. 2001), Tnfsf10 expression was positively associated with Nkg2d expression (Fig. 5D) and negatively with tumour weight (Fig. 5E).

\section{Discussion}

In this study, we have extended our previous observations that tissue IGFBP-3 stimulates EO771 mammary tumour growth in C57BL/6 mice, by characterising a potential immune mechanism by which this might occur. As previously reviewed, the growth-inhibitory effects of IGFBP-3 are well known from a wide variety of cell-line research as well as clinical studies in which the suppression of IGFBP3 is associated with poor patient outcome (Firth \& Baxter 2002, Baxter 2014). Examples of cancers in 
A

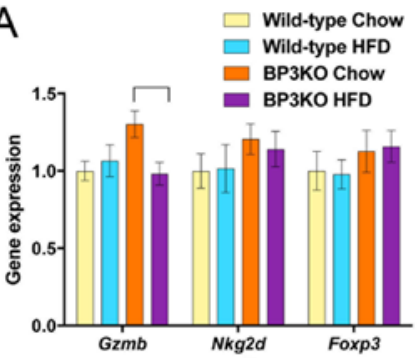

C

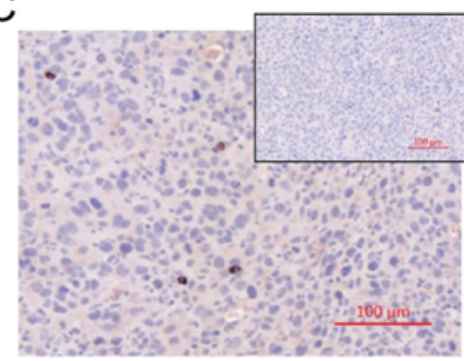

E

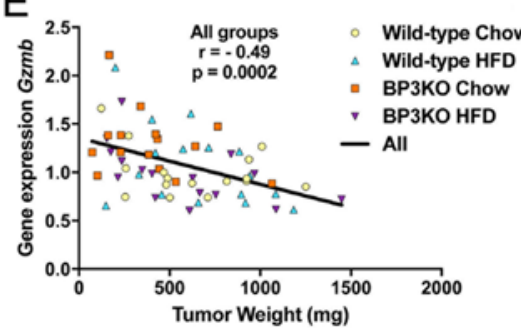

B

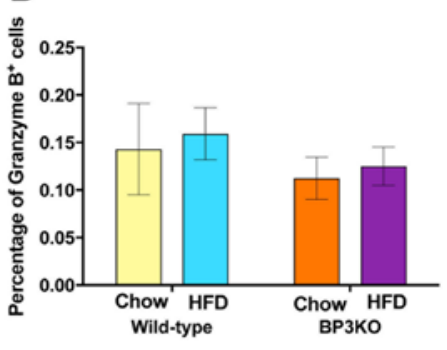

D
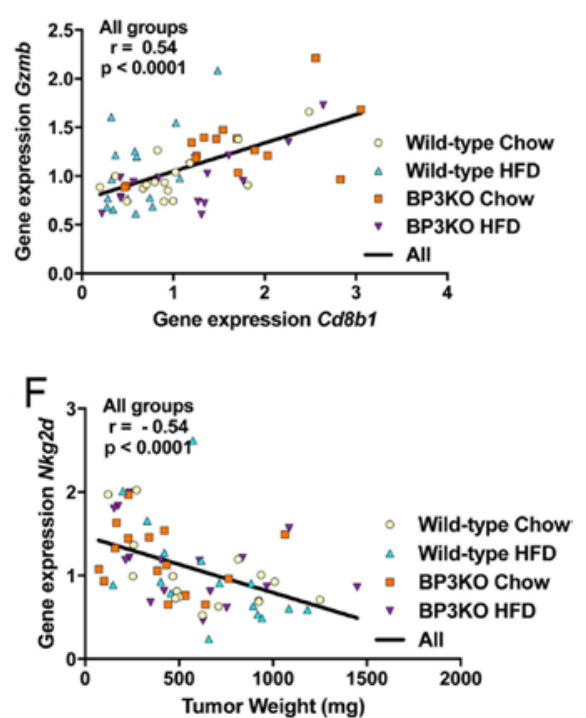

Figure 4 Expression of markers associated with T cells and natural killer cells. (A) Intratumoural expression of Gzmb is not different overall between wild-type and BP3KO mice but is reduced with HFD in BP3KO mice ( $P=0.024$ for interaction). Intratumoural gene expression of the regulatory $T$ cell marker, Foxp3, and the natural killer cell marker, Nkg2d, were not different among treatment groups. (B) Granzyme $B$ expression was similar in tumours across groups by IHC detection. (C) Representative images of a tumour section stained positively for granzyme B and the associated isotype control-stained tumour section (inset). Gzmb expression in the tumours is (D) positively associated with $C d 8 b 1$ expression and (E) negatively associated with tumour weight across all groups. (F) $N k g 2 d$ expression is negatively associated with tumour growth. Data were analysed by 2-way ANOVA or by Spearman's correlation test and are shown as means \pm S.E.M., $n=15-16$ per group. Brackets indicate groups that are significantly different by post hoc Tukey's test. which IGFBP-3 has an apparent tumour-suppressive role include hepatocellular carcinoma (Aishima et al. 2006) and non-small cell lung cancer (Chang et al. 2002). These growth-inhibitory activities may occur both through suppression of IGF1R signalling and by IGF1Rindependent mechanisms (Baxter 2014). In contrast, IGFBP-3 is growth-stimulatory in some cancer cell-line models (Baxter 2014), mediated in part by sphingosine kinase and EGFR activation (Martin et al. 2014), and its high tumour expression has been associated with disease recurrence and/or poor patient outcome - for example in glioblastoma (Santosh et al. 2010), prostate cancer (Seligson et al. 2013) and breast cancer (Yu et al. 1998, Sheen-Chen et al. 2009). However, the precise role and prognostic significance of tumour IGFBP-3 expression in different cancers remain clouded by conflicting results (Baxter 2014), and a different model of breast tumourigenesis in Igfbp3-null mice supported a tumoursuppressive, rather than a growth-stimulatory, role for host-derived IGFBP-3 (Blouin et al. 2015).

The findings detailed in this study shed new light on the observation that the reduced EO771 tumour growth in the absence of circulating or stromal IGFBP-3 was associated with increased $\mathrm{CD}^{+} \mathrm{T}$ cell abundance. As the EO771 tumour cells used in this study lack detectable expression of IGFBP-3, overall tumoural expression of IGFBP-3 in WT host mice provided an estimate of the contribution of IGFBP-3 within the tumour stroma. An increased stromal expression of IGFBP-3 was positively associated with tumour growth, supporting the hypothesis that IGFBP-3 in the microenvironment promotes tumour progression. This is consistent with clinical observations based on whole patient tumours which are composed of both epithelial and stromal compartments, where the increased protein or gene expression of IGFBP-3 was associated with greater tumour growth and poor prognosis (Rocha et al. 1996, 1997). Analysis of the specific IGFBP-3-expressing cells within these tumours might provide further information about which cell types in the tumour microenvironment contribute to IGFBP-3-dependent tumour progression. In contrast to the relationship between stromal IGFBP-3 expression and tumour growth, there was no apparent relationship between circulating levels of IGFBP-3 and tumour growth. This is in agreement with the observation that there is a lack of consistency in the evidence relating circulating IGFBP-3 to tumour growth (Baxter 2014). 

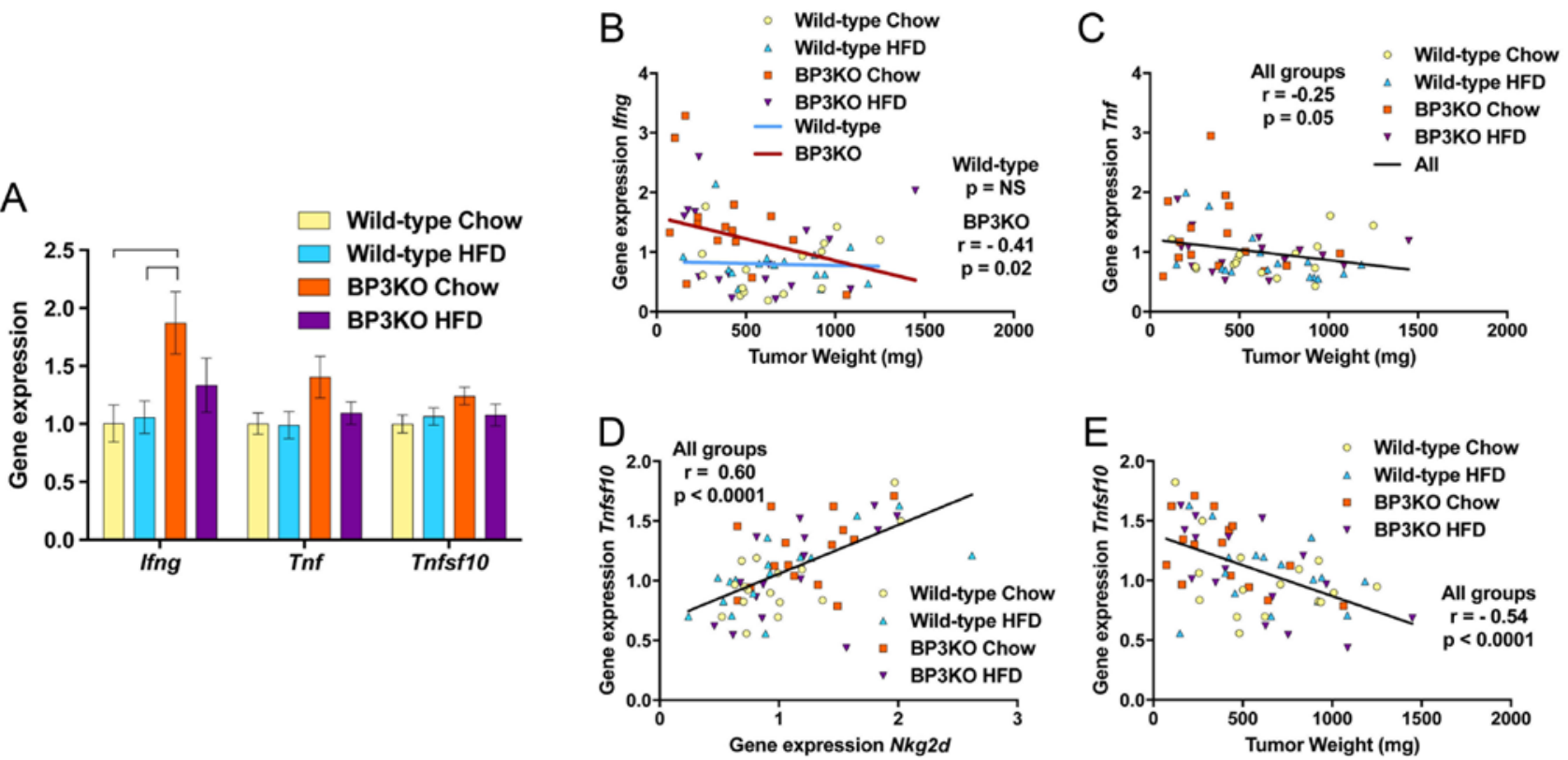

Figure 5

Cytokines associated with anti-tumour activity are increased in tumours from BP3KO mice. (A) Tumoural gene expressions of (A) Ifng and Tnf are increased in the absence of IGFBP-3 (Ifng: $P=0.008$ and Tnf: $P=0.049$ for genotype). Tumoural gene expression of Tnfsf10, which encodes TRAIL, is similar across treatment groups. (B) The increased expression of Ifng in BP3KO but not wild-type mice is associated with decreased tumour weight. (C) Increased expression of $\operatorname{Tnf}$ is associated with decreased tumour weight. (D) Expression of Tnfsf10 is positively associated with gene expression of the natural killer cell marker, Nkg2d, and (E) negatively associated with tumour weight. Data were analysed by 2-way ANOVA or by Spearman's correlation test and are shown as means \pm S.E.M., $n=15-16$ per group. Brackets indicate groups that are significantly different by post hoc Tukey's test.

Notably, intratumoural IFN $\gamma$ mRNA levels were nearly twice as high in the BP3KO mice on a chow diet compared to WT mice. In addition to increased IFN $\gamma$ expression, tumours from chow-fed BP3KO mice also showed increased gene expression of TNF relative to WT mice. Both IFN $\gamma$ and TNF have been described to have context-dependent roles in cancer progression and have been implicated in the infiltration and activity of intratumoural immune cells (Balkwill 2009, Zaidi \& Merlino 2011). In particular, the increased presence of IFN $\gamma$ and TNF has been demonstrated to inhibit tumour growth through the induction of cell cycle arrest in $G_{1} / G_{0}$ by the activation of $\mathrm{p} 16^{\mathrm{INK} 4 \mathrm{a}}$ and hypophosphorylation of $\mathrm{Rb}$ (Braumuller et al. 2013). Consistent with its tumour growth-inhibitory effect in the literature, the expression of IFN $\gamma$ was also negatively associated with tumour growth in this study.

$C d 8 a$ and $C d 8 b 1$ gene expression was increased in the tumours grown in the BP3KO mice and this was confirmed at the protein level for CD8 $\alpha$ using IHC. In concordance with the literature in which a high percentage of tumourinfiltrating lymphocytes is positively associated with survival in women with breast cancer (Mahmoud etal.2011, Ali et al. 2014), the increased presence of intratumoural
$\mathrm{CD}^{+} \mathrm{T}$ cells was associated with decreased tumour growth in our study. $\mathrm{CD}^{+} \mathrm{T}$ cells promote anti-tumour activity owing to their ability to secrete tumouricidal and growthinhibitory factors such as granzymes, as well as cytokines including IFN $\gamma$ and TNF (Appay et al. 2008). Therefore, to gain insight into the potential for anti-tumour function of these cells, granzyme B, a cytolytic enzyme associated with T cells (Appay et al. 2008) was examined. Granzyme $\mathrm{B}$ is a serine protease which is capable of causing DNA fragmentation and the stimulation of caspase activity in the target cell (Afonina et al. 2010), and has been used as a surrogate marker for functional cytotoxic $\mathrm{T}$ cells. Accordingly, granzyme B mRNA expression was positively associated with $C d 8 b 1$ expression and inversely associated with tumour weight. However, despite the differences in CD8 expression observed, the expression of granzyme B was not significantly different between WT and BP3KO genotypes irrespective of diet.

The lack of difference in granzyme B expression between groups suggests that the $\mathrm{T}$ cells present are not fully activated for effector function or that other effector molecules are more important in this model. This may be through the presence of immunosuppressive factors in the tumour microenvironment. For example, the presence 
of transforming growth factor- $\beta$ (TGF $\beta$ ) in the tumour microenvironment has been shown to suppress IFN $\gamma$ and granzyme B expression in $\mathrm{T}$ cells (Thomas \& Massague 2005) with the TGF $\beta$-signalling pathway proteins, Smads, having been shown to bind to the promoters of both IFN $\gamma$ and granzyme B (Thomas \& Massague 2005). Blockade of TGF $\beta$ signalling has been shown to restore IFN $\gamma$ and granzyme B expression in T cells (Thomas \& Massague 2005). The increased IFN $\gamma$ mRNA levels seen in BP3KO mice are thus consistent with our earlier observation that IGFBP-3 can activate the TGF $\beta$ receptor system to enhance Smad signalling in breast cancer cells (Fanayan et al. 2002). Another possible mechanism by which immunosuppressive factors within the tumour microenvironment might have an effect on granzyme B expression is the upregulation of PD-L1 with tumour development and the concomitant increased stimulation of its receptor, PD- 1 , on T cells, where blockade with anti-PD-L1 therapy led to increased granzyme B expression (Zippelius et al. 2015). PD-L1, which is inducible with IFN $\gamma$ in the EO771 model, is highly upregulated and likely constitutes a key contributor to the aggressive tumour growth observed with the EO771 model, as anti-PD-1 treatment has been demonstrated to result in drastic inhibition of tumour growth in this model (Gray et al. 2016). The unexpectedly similar expression of granzyme B among the treatment groups in our study may, therefore, be a result of the engagement of immunosuppressive mechanisms.

FOXP3 is a marker of regulatory $\mathrm{T}$ cells (Treg) which are a subset of $\mathrm{CD} 44^{+} \mathrm{T}$ cells that have been implicated in the suppression of cytotoxic T cell activity (Shevach 2009). The EO771 model has previously been demonstrated to show an increase in the number of FOXP3 ${ }^{+}$cells as tumour growth progresses, suggesting that suppression of an anti-tumour response via increased numbers of Treg cells occurs in this model (Huang et al. 2015). Tumoural Foxp3 levels were similar between groups suggesting that the accumulation of Tregs in the tumour microenvironment was unaffected by IGFBP-3 expression or by exposure to high fat feeding. In agreement with the literature showing that increased NK cell number and activity is associated with better prognosis in breast cancer patients (Mamessier et al. 2011, Ascierto et al. 2013), the increased presence of cells expressing $N k g 2 d$, a marker of activated NK cells, was associated with decreased tumour weight in this study. The presence of NK cells was examined as there is much interest in targeting NK cell function as a therapeutic strategy. Reasons for this interest include the ability of NK cells to kill target cells that may be resistant to cytotoxic $\mathrm{T}$ cell-mediated death because of a low expression of MHC I molecules (Vivier et al. 2012) as well as the ability to detect cells under stress which may be caused by stressors such as DNA damage (Vivier et al. 2012). NK cells are clearly involved in tumour immunosurveillance, and the presence and function of NK cells have also been shown to be important for anti-metastatic activity (Rautela et al. 2015, Bottos et al. 2016), including via interferons and/or NK cell-expressed TRAIL (Smyth et al. 2001, Sedger et al. 2002). Human NK cells can be segregated into two subsets based on their expression of the cell adhesion protein CD56. The two subsets, CD56 bright and CD56 dim, have been shown to vary in terms of their expression of receptors, proliferative capacity and distribution among tissues (Melsen et al. 2016). While characterisation of the functional differences between the two subsets has been difficult due to lack of expression of CD56 in NK cells in model organisms such as mice (Melsen et al. 2016), profiling of human NK cells by gene expression and cytokine secretion has revealed that CD56 dim cells differ from CD56 bright cells in terms of IGFBP-3 and IGF-1 production (Wendt et al. 2006). Although overall tumoural mRNA expression of $N k g 2 d$ between WT and BP3KO mice was not significantly different in this study, TRAIL expression was strongly associated with $N k g 2 d$ expression, and negatively with tumour weight, suggesting that further investigation into how IGFBP-3 might affect NK cell tumouricidal activity and tumour immune surveillance is warranted.

The intratumoural accumulation of $\mathrm{T}$ cells in the absence of IGFBP-3 suggests that host IGFBP-3 is potentially inhibitory to $\mathrm{T}$ cell infiltration. In agreement with this notion, the administration of recombinant IGFBP-3 or transgenic overexpression of IGFBP-3 to ovalbumintreated mice (a mouse model of asthma) led to reduced accumulation of immune cells such as eosinophils, lymphocytes and neutrophils in bronchoalveolar lavage fluid (Lee et al. 2011). The IGFBP-3-associated suppression of immune cell infiltration was proposed to be mediated through the inhibition of TNF signalling which has been implicated in immune cell chemotaxis (Lee et al. 2011). It is also possible that IGFBP-3 suppresses intratumoural $\mathrm{T}$ cell accumulation by promoting the accrual of myeloidderived suppressor cells (MDSCs). Using mouse models of oesophageal cancer, the secretion of IGFBP-3 in conjunction with other cytokines was shown to promote the differentiation of bone marrow progenitor cells into CD38 high MDSCs, which possess an enhanced capacity for immunosuppression compared to CD38 $8^{\text {low }}$ cells, and were further demonstrated to promote tumour growth (Karakasheva et al. 2015). 
The tumour-suppressive effect of IGFBP-3 deficiency was reduced with exposure to HFD, with the exposure of BP3KO mice to HFD associated with a reversal of the increased abundance of CD8+ $\mathrm{T}$ cells in the tumours. This finding is consistent with the association of the obese phenotype with decreased immune function (Kanneganti \& Dixit 2012) which is exemplified by an increased susceptibility to infections including influenza in obese individuals and rodent models (Milner \& Beck 2012). Mechanisms proposed to explain the decreased immune function observed with obesity include alterations in the function of macrophages (Zhou et al. 2009) and T cells as well as $\mathrm{T}$ cell number (Yang et al. 2009, Kanneganti \& Dixit 2012). In particular, diet-induced obesity has been linked to the decreased development of an anti-tumour immune response through the impairment of dendritic cell function (James et al. 2012). In addition to these mechanisms, obesity may also potentially influence immune function by affecting the proliferation and differentiation of haematopoietic stem cells which are the precursors to immune cells (Adler et al. 2014). Impairment in immune function may, thus, explain the obesity-associated reduction in the tumour growthsuppressive effects of IGFBP-3 deficiency.

In conclusion, the results of this study provide an unexpected immune-based mechanism by which host IGFBP-3 may contribute to breast tumour growth in the EO771 murine breast cancer model. The marked increase in $\mathrm{CD}^{+}$cells in tumours growing in $\mathrm{BP} 3 \mathrm{KO}$ mice supports a T-cell-mediated growth-inhibitory effect of IGFBP-3 deficiency, although the signalling pathways by which host IGFBP-3 discourages $T$ cell accumulation in the tumour remain to be determined. The reversal of this effect in mice fed a HFD is consistent with the known impairment of immune function in obesity and further supports the concept that IGFBP-3 links the development of obesity to breast cancer progression. In addition, the data suggest that the detailed analysis of ligand and receptor expression in individual cells, possibly via flow cytometry, as a means of determining immune cell subtype and effector molecule expression is warranted to better understand immune control of this tumour model. A greater understanding of how IGFBP-3 modulates NK and T cell abundance as well as function in breast cancer may offer new opportunities for tumour immunomodulation based on the targeting of IGFBP-3dependent signalling.
Declaration of interests

The authors declare that there is no conflict of interest that could be perceived as prejudicing the impartiality of the research reported.

\section{Funding}

This research did not receive any specific grant from any funding agency in the public, commercial or not-for-profit sector.

\section{Author contribution statement}

T S, C D S and R C B designed the study and contributed to the data analysis, T S collected the primary data and prepared the initial manuscript draft and all authors contributed to the interpretation of data and the editing of the manuscript. All authors read and approved the final manuscript.

\section{Acknowledgements}

The authors acknowledge the assistance of the Kearns Animal Facility and the Histology Facility at the Kolling Institute in these studies.

\section{References}

Adler BJ, Kaushansky K \& Rubin CT 2014 Obesity-driven disruption of haematopoiesis and the bone marrow niche. Nature Reviews Endocrinology 10 737-748. (https://doi.org/10.1038/nrendo.2014.169)

Afonina IS, Cullen SP \& Martin SJ 2010 Cytotoxic and non-cytotoxic roles of the CTL/NK protease granzyme B. Immunological Reviews $\mathbf{2 3 5}$ 105-116. (https://doi.org/10.1111/j.0105-2896.2010.00908.x)

Aishima S, Basaki Y, Oda Y, Kuroda Y, Nishihara Y, Taguchi K, Taketomi A, Maehara Y, Hosoi F, Maruyama Y, et al. 2006 High expression of insulin-like growth factor binding protein-3 is correlated with lower portal invasion and better prognosis in human hepatocellular carcinoma. Cancer Science 97 1182-1190. (https://doi. org/10.1111/j.1349-7006.2006.00322.x)

Ali HR, Provenzano E, Dawson SJ, Blows FM, Liu B, Shah M, Earl HM, Poole CJ, Hiller L, Dunn JA, et al. 2014 Association between CD8+ T-cell infiltration and breast cancer survival in 12,439 patients. Annals of Oncology 25 1536-1543. (https://doi.org/10.1093/annonc/ mdu191)

Appay V, Douek DC \& Price DA 2008 CD8+ T cell efficacy in vaccination and disease. Nature Medicine 14 623-628. (https://doi. org/10.1038/nm.f.1774)

Ascierto ML, Idowu MO, Zhao Y, Khalak H, Payne KK, Wang XY, Dumur CI, Bedognetti D, Tomei S, Ascierto PA, et al. 2013 Molecular signatures mostly associated with NK cells are predictive of relapse free survival in breast cancer patients. Journal of Translational Medicine 11 145. (https://doi.org/10.1186/1479-5876-11-145)

Balkwill F 2009 Tumour necrosis factor and cancer. Nature Reviews Cancer 9 361-371. (https://doi.org/10.1038/nrc2628)

Baxter RC 2014 IGF binding proteins in cancer: mechanistic and clinical insights. Nature Reviews Cancer 14 329-341. (https://doi.org/10.1038/ nrc3720)

Blouin MJ, Bazile M, Birman E, Zakikhani M, Florianova L, Aleynikova O, Powell DR \& Pollak M 2015 Germ line knockout of IGFBP-3 reveals influences of the gene on mammary gland neoplasia. Breast Cancer Research and Treatment 149 577-585. (https://doi.org/10.1007/s10549-015-3268-8) 
Bottos A, Gotthardt D, Gill JW, Gattelli A, Frei A, Tzankov A, Sexl V, Wodnar-Filipowicz A \& Hynes NE 2016 Decreased NK-cell tumour immunosurveillance consequent to JAK inhibition enhances metastasis in breast cancer models. Nature Communications 712258 (https://doi.org/10.1038/ncomms12258)

Braumuller H, Wieder T, Brenner E, Assmann S, Hahn M, Alkhaled M, Schilbach K, Essmann F, Kneilling M, Griessinger C, et al. 2013 T-helper-1-cell cytokines drive cancer into senescence. Nature 494 361-365. (https://doi.org/10.1038/nature11824)

Chan DS, Vieira AR, Aune D, Bandera EV, Greenwood DC, McTiernan A, Navarro Rosenblatt D, Thune I, Vieira R \& Norat T 2014 Body mass index and survival in women with breast cancer-systematic literature review and meta-analysis of 82 follow-up studies. Annals of Oncology 25 1901-1914. (https://doi.org/10.1093/annonc/mdu042)

Chang YS, Kong G, Sun S, Liu D, El-Naggar AK, Khuri FR, Hong WK \& Lee HY 2002 Clinical significance of insulin-like growth factorbinding protein-3 expression in stage I non-small cell lung cancer. Clinical Cancer Research 8 3796-3802.

Denkert C, Loibl S, Noske A, Roller M, Muller BM, Komor M, Budczies J, Darb-Esfahani S, Kronenwett R, Hanusch C, et al. 2010 Tumorassociated lymphocytes as an independent predictor of response to neoadjuvant chemotherapy in breast cancer. Journal of Clinical Oncology 28 105-113. (https://doi.org/10.1200/JCO.2009.23.7370)

Fanayan S, Firth SM \& Baxter RC 2002 Signaling through the Smad pathway by insulin-like growth factor-binding protein-3 in breast cancer cells. Relationship to transforming growth factor-beta 1 signaling. Journal of Biological Chemistry 277 7255-7261. (https://doi. org/10.1074/jbc.M108038200)

Firth SM \& Baxter RC 2002 Cellular actions of the insulin-like growth factor binding proteins. Endocrine Reviews 23 824-854. (https://doi. org/10.1210/er.2001-0033)

Goodwin PJ, Ennis M, Pritchard KI, Trudeau ME, Koo J, Hartwick W, Hoffma B \& Hood N 2002 Insulin-like growth factor binding proteins 1 and 3 and breast cancer outcomes. Breast Cancer Research and Treatment 74 65-76. (https://doi.org/10.1023/A:1016075709022)

Gray MJ, Gong J, Hatch MM, Nguyen V, Hughes CC, Hutchins JT \& Freimark BD 2016 Phosphatidylserine-targeting antibodies augment the anti-tumorigenic activity of anti-PD-1 therapy by enhancing immune activation and downregulating pro-oncogenic factors induced by T-cell checkpoint inhibition in murine triple-negative breast cancers. Breast Cancer Research 18 50. (https://doi.org/10.1186/ s13058-016-0708-2)

Huang Y, Ma C, Zhang Q, Ye J, Wang F, Zhang Y, Hunborg P, Varvares MA, Hoft DF, Hsueh EC, et al. 2015 CD4+ and CD8+ T cells have opposing roles in breast cancer progression and outcome. Oncotarget 6 17462-17478. (https://doi.org/10.18632/ oncotarget.3958)

Ibrahim EM, Al-Foheidi ME, Al-Mansour MM \& Kazkaz GA 2014 The prognostic value of tumor-infiltrating lymphocytes in triple-negative breast cancer: a meta-analysis. Breast Cancer Research and Treatment 148 467-476. (https://doi.org/10.1007/s10549-014-3185-2)

Iyengar NM, Hudis CA \& Dannenberg AJ 2015 Obesity and cancer: local and systemic mechanisms. Annual Review of Medicine 66 297-309. (https://doi.org/10.1146/annurev-med-050913-022228)

James BR, Tomanek-Chalkley A, Askeland EJ, Kucaba T, Griffith TS \& Norian LA 2012 Diet-induced obesity alters dendritic cell function in the presence and absence of tumor growth. Journal of Immunology 189 1311-1321. (https://doi.org/10.4049/jimmunol.1100587)

Kanneganti TD \& Dixit VD 2012 Immunological complications of obesity. Nature Immunology 13 707-712. (https://doi.org/10.1038/ ni.2343)

Karakasheva TA, Waldron TJ, Eruslanov E, Kim SB, Lee JS, O’Brien S, Hicks PD, Basu D, Singhal S, Malavasi F, et al. 2015 CD38-expressing myeloid-derived suppressor cells promote tumor growth in a murine model of esophageal cancer. Cancer Research 75 4074-4085. (https://doi.org/10.1158/0008-5472.CAN-14-3639)
Kroemer G, Senovilla L, Galluzzi L, Andre F \& Zitvogel L 2015 Natural and therapy-induced immunosurveillance in breast cancer. Nature Medicine 21 1128-1138. (https://doi.org/10.1038/nm.3944)

Lee YC, Jogie-Brahim S, Lee DY, Han J, Harada A, Murphy LJ \& Oh Y 2011 Insulin-like growth factor-binding protein-3 (IGFBP-3) blocks the effects of asthma by negatively regulating NF-kappaB signaling through IGFBP-3R-mediated activation of caspases. Journal of Biological Chemistry 286 17898-17909. (https://doi.org/10.1074/jbc. M111.231035)

Mahmoud SM, Paish EC, Powe DG, Macmillan RD, Grainge MJ, Lee AH, Ellis IO \& Green AR 2011 Tumor-infiltrating CD8+ lymphocytes predict clinical outcome in breast cancer. Journal of Clinical Oncology 29 1949-1955. (https://doi.org/10.1200/JCO.2010.30.5037)

Mamessier E, Sylvain A, Thibult ML, Houvenaeghel G, Jacquemier J, Castellano R, Goncalves A, Andre P, Romagne F, Thibault G, et al. 2011 Human breast cancer cells enhance self tolerance by promoting evasion from NK cell antitumor immunity. Journal of Clinical Investigation 121 3609-3622. (https://doi.org/10.1172/JCI45816)

Martin JL, de Silva HC, Lin MZ, Scott CD \& Baxter RC 2014 Inhibition of insulin-like growth factor-binding protein-3 signaling through sphingosine kinase-1 sensitizes triple-negative breast cancer cells to EGF receptor blockade. Molecular Cancer Therapeutics 13 316-328. (https://doi.org/10.1158/1535-7163.MCT-13-0367)

Matsushita H, Hosoi A, Ueha S, Abe J, Fujieda N, Tomura M, Maekawa R, Matsushima K, Ohara O \& Kakimi K 2015 Cytotoxic T lymphocytes block tumor growth both by lytic activity and IFNgamma-dependent cell-cycle arrest. Cancer Immunology Research $\mathbf{3}$ 26-36. (https://doi.org/10.1158/2326-6066.CIR-14-0098)

Melsen JE, Lugthart G, Lankester AC \& Schilham MW 2016 Human circulating and tissue-resident CD56(bright) natural killer cell populations. Frontiers in Immunology 7 262. (https://doi.org/10.3389/ fimmu.2016.00262)

Milner JJ \& Beck MA 2012 The impact of obesity on the immune response to infection. Proceedings of the Nutrition Society 71 298-306. (https://doi.org/10.1017/S0029665112000158)

Ning Y, Schuller AG, Bradshaw S, Rotwein P, Ludwig T, Frystyk J \& Pintar JE 2006 Diminished growth and enhanced glucose metabolism in triple knockout mice containing mutations of insulinlike growth factor binding protein-3, -4 , and -5 . Molecular Endocrinology 20 2173-2186. (https://doi.org/10.1210/me.2005-0196)

Park J, Morley TS, Kim M, Clegg DJ \& Scherer PE 2014 Obesity and cancer - mechanisms underlying tumour progression and recurrence. Nature Reviews Endocrinology 10 455-465. (https://doi.org/10.1038/ nrendo.2014.94)

Protani M, Coory M \& Martin JH 2010 Effect of obesity on survival of women with breast cancer: systematic review and meta-analysis. Breast Cancer Research and Treatment 123 627-635. (https://doi. org/10.1007/s10549-010-0990-0)

Rautela J, Baschuk N, Slaney CY, Jayatilleke KM, Xiao K, Bidwell BN, Lucas EC, Hawkins ED, Lock P, Wong CS, et al. 2015 Loss of host Type-I IFN signaling accelerates metastasis and impairs NK-cell antitumor function in multiple models of breast cancer. Cancer Immunology Research 3 1207-1217. (https://doi.org/10.1158/23266066.CIR-15-0065)

Renehan AG, Zwahlen M \& Egger M 2015 Adiposity and cancer risk: new mechanistic insights from epidemiology. Nature Reviews Cancer 15 484-498. (https://doi.org/10.1038/nrc3967)

Renehan AG, Zwahlen M, Minder C, O'Dwyer ST, Shalet SM \& Egger M 2004 Insulin-like growth factor (IGF)-I, IGF binding protein-3, and cancer risk: systematic review and meta-regression analysis. Lancet 363 1346-1353. (https://doi.org/10.1016/S01406736(04)16044-3)

Rocha RL, Hilsenbeck SG, Jackson JG, Lee AV, Figueroa JA \& Yee D 1996 Correlation of insulin-like growth factor-binding protein-3 messenger RNA with protein expression in primary breast cancer tissues: detection of higher levels in tumors with poor prognostic 
features. Journal of the National Cancer Institute 88 601-606. (https://doi.org/10.1093/jnci/88.9.601)

Rocha RL, Hilsenbeck SG, Jackson JG, VanDenBerg CL, Weng C, Lee AV \& Yee D 1997 Insulin-like growth factor binding protein-3 and insulin receptor substrate-1 in breast cancer: correlation with clinical parameters and disease-free survival. Clinical Cancer Research 3 103-109.

Rowlands MA, Holly JM, Gunnell D, Gilbert R, Donovan J, Lane JA, Marsden G, Collin SM, Hamdy F, Neal DE, et al. 2010 The relation between adiposity throughout the life course and variation in IGFs and IGFBPs: evidence from the ProtecT (Prostate testing for cancer and Treatment) study. Cancer Causes and Control 21 1829-1842. (https://doi.org/10.1007/s10552-010-9610-x)

Santosh V, Arivazhagan A, Sreekanthreddy P, Srinivasan H, Thota B, Srividya MR, Vrinda M, Sridevi S, Shailaja BC, Samuel C, et al. 2010 Grade-specific expression of insulin-like growth factor-binding proteins-2, -3 , and -5 in astrocytomas: IGFBP-3 emerges as a strong predictor of survival in patients with newly diagnosed glioblastoma. Cancer Epidemiology, Biomarkers and Prevention 19 1399-1408. (https://doi.org/10.1158/1055-9965.EPI-09-1213)

Savas P, Salgado R, Denkert C, Sotiriou C, Darcy PK, Smyth MJ \& Loi S 2016 Clinical relevance of host immunity in breast cancer: from TILs to the clinic. Nature Reviews Clinical Oncology 13 228-241. (https:// doi.org/10.1038/nrclinonc.2015.215)

Scully T, Firth SM, Scott CD, de Silva HC, Pintar JE, Chan-Ling T, Twigg SM \& Baxter RC 2016 Insulin-like growth factor binding protein-3 links obesity and breast cancer progression. Oncotarget 7 55491-55505. (https://doi.org/10.18632/oncotarget.10675)

Sedger LM, Glaccum MB, Schuh JC, Kanaly ST, Williamson E, Kayagaki N, Yun T, Smolak P, Le T, Goodwin R, et al. 2002 Characterization of the in vivo function of TNF-alpha-related apoptosis-inducing ligand, TRAIL/Apo2L, using TRAIL/Apo2L gene-deficient mice. European Journal of Immunology 32 2246-2254. (https://doi.org/10.1002/15214141(200208)32:8<2246::AID-IMMU2246>3.0.CO;2-6)

Sedger LM, Shows DM, Blanton RA, Peschon JJ, Goodwin RG, Cosman D \& Wiley SR 1999 IFN-gamma mediates a novel antiviral activity through dynamic modulation of TRAIL and TRAIL receptor expression. Journal of Immunology 163 920-926.

Seligson DB, Yu H, Tze S, Said J, Pantuck AJ, Cohen P \& Lee KW 2013 IGFBP-3 nuclear localization predicts human prostate cancer recurrence. Hormones and Cancer 4 12-23. (https://doi.org/10.1007/ s12672-012-0124-8)

Sheen-Chen SM, Zhang H, Huang CC \& Tang RP 2009 Insulin-like growth factor-binding protein-3 in breast cancer: analysis with tissue microarray. Anticancer Research 29 1131-1135.
Shevach EM 2009 Mechanisms of foxp3+ T regulatory cell-mediated suppression. Immunity 30 636-645. (https://doi.org/10.1016/j. immuni.2009.04.010)

Smyth MJ, Cretney E, Takeda K, Wiltrout RH, Sedger LM, Kayagaki N, Yagita H \& Okumura K 2001 Tumor necrosis factor-related apoptosisinducing ligand (TRAIL) contributes to interferon gamma-dependent natural killer cell protection from tumor metastasis. Journal of Experimental Medicine 193 661-670. (https://doi.org/10.1084/ jem.193.6.661)

Thomas DA \& Massague J 2005 TGF-beta directly targets cytotoxic T cell functions during tumor evasion of immune surveillance. Cancer Cell 8 369-380. (https://doi.org/10.1016/j.ccr.2005.10.012)

Vivier E, Ugolini S, Blaise D, Chabannon C \& Brossay L 2012 Targeting natural killer cells and natural killer $\mathrm{T}$ cells in cancer. Nature Reviews Immunology 12 239-252. (https://doi.org/10.1038/ nri3174)

Wendt K, Wilk E, Buyny S, Buer J, Schmidt RE \& Jacobs R 2006 Gene and protein characteristics reflect functional diversity of CD56dim and CD56bright NK cells. Journal of Leukocyte Biology 80 1529-1541. (https://doi.org/10.1189/jlb.0306191)

Yang H, Youm YH, Vandanmagsar B, Rood J, Kumar KG, Butler AA \& Dixit VD 2009 Obesity accelerates thymic aging. Blood 114 3803-3812. (https://doi.org/10.1182/blood-2009-03-213595)

Yu H, Levesque MA, Khosravi MJ, Papanastasiou-Diamandi A, Clark GM \& Diamandis EP 1996 Associations between insulin-like growth factors and their binding proteins and other prognostic indicators in breast cancer. British Journal of Cancer 74 1242-1247. (https://doi. org/10.1038/bjc.1996.523)

Yu H, Levesque MA, Khosravi MJ, Papanastasiou-Diamandi A, Clark GM \& Diamandis EP 1998 Insulin-like growth factor-binding protein-3 and breast cancer survival. International Journal of Cancer 79 624-628. (https://doi.org/10.1002/(SICI)1097-0215(19981218)79:6<624::AIDIJC12>3.0.CO;2-9)

Zaidi MR \& Merlino G 2011 The two faces of interferon-gamma in cancer. Clinical Cancer Research 17 6118-6124. (https://doi. org/10.1158/1078-0432.CCR-11-0482)

Zhou Q, Leeman SE \& Amar S 2009 Signaling mechanisms involved in altered function of macrophages from diet-induced obese mice affect immune responses. PNAS 106 10740-10745. (https://doi. org/10.1073/pnas.0904412106)

Zippelius A, Schreiner J, Herzig P \& Muller P 2015 Induced PD-L1 expression mediates acquired resistance to agonistic anti-CD40 treatment. Cancer Immunology Research 3 236-244. (https://doi. org/10.1158/2326-6066.CIR-14-0226)

Received in final form 19 October 2017

Accepted 31 October 2017 